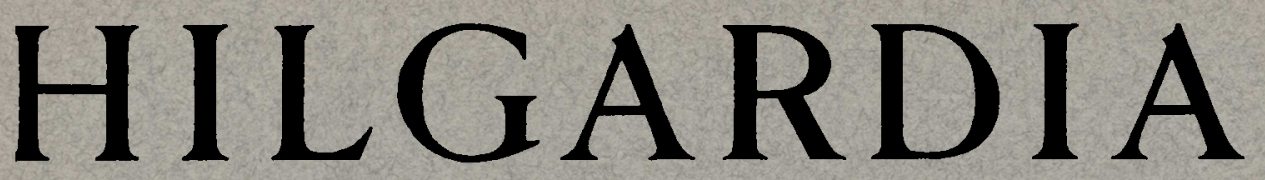

A Journal of Agricultural Science Published by the California Agricultural Experiment Station

\title{
BANG'S DISEASE IN A NATURALLY INFECTED HERD
}

\author{
F. M. HAYES AND E. H. BARGER
}

\section{BRUCELLA ABORTUS SHEDDER CONDITIONS IN TWENTY COWS}

B. S. HENRY, C. M. HARING, AND J. TRAUM

This issue completes Volume 9 


\title{
$\begin{array}{lllllllll}H & \text { I } & \text { L } & G & \text { A } & \text { R } & \text { D } & \text { I } & \text { A }\end{array}$
}

A Journal of Agricultural Science Published by

the California Agricultural Experiment Station

\begin{tabular}{lll}
\hline VoL. 9 & NOVEMBER, 1935 & No. 11 \\
\hline
\end{tabular}

\section{BANG'S DISEASE IN A NATURALLY INFECTED HERD $^{1}$}

\author{
F. M. HAYES ${ }^{2}$ AND E. H. BARGER 3
}

The STUdies to be reported herein were begun in 1922 in a herd of dairy cattle in which 19.0 per cent of the animals were infected with Brucella abortus, as indicated by the agglutination test of the blood serum. The particular objects were to determine what correlation exists between agglutinins in the blood and those in the milk, and what relation these agglutinins bear to the presence of the organisms in the milk and in the products of normally or prematurely terminated pregnancies.

Unfortunately the herd upon which these observations were made was not maintained solely for the purpose of these investigations, and the procedures carried out were necessarily limited in scope and in many cases were terminated by death or disposal of the animals or by their use for other purposes before conclusions could be drawn. However, certain of the animals have contributed significant data.

Previous to 1922 this herd was known to be infected with Bang's disease. Occasional abortions had occurred and agglutination tests on the blood had proved positive, but since there were no alarming symptoms of the disease, no particular effort was made to blood-test the animals systematically and regularly. The aborters were isolated until uterine discharges ceased and were then returned to the herd. From 1922, when 19.0 per cent were discovered to be reactors to the test, to 1926 , more hygienic procedures were practiced with the aborters and the positivereacting cows that calved normally, in an effort to control the spread of the disease. The disease remained stationary during 1923 and 1924 and increased in virulence in 1925 and 1926, and in these latter years reached one of the typical peaks that is characteristic of infected herds. Circum-

\footnotetext{
${ }^{1}$ Received for publication July 9, 1935.

${ }^{2}$ Professor of Veterinary Science and Veterinarian in the Experiment Station.

${ }^{3}$ Junior Veterinarian in the Experiment Station. Resigned May, 1928.
} 
stantial evidence only, is available to account for the rise in the number of reactors and aborters in 1925 through the addition to the old herd in the spring of 1923 of 34 animals from another herd, 9 of which were reactors to the agglutination test.

\section{METHODS}

Blood and milk samples were collected on the same day at intervals of approximately 90 days, sometimes oftener. The blood and milk serums were then subjected to the agglutination test in the same dilutions with the same antigens. The greater part of the approximately $400 \mathrm{cc}$ of the milk not used for the agglutination test was centrifuged and the sediment injected intraperitoneally into two guinea pigs. Whenever an abortion or a normal calving occurred, appropriate material was cultured for Brucella abortus on glycerine glucose gentian-violet agar, and two guinea pigs injected intraperitoneally with a salt-solution suspension of the material. Guinea pigs were killed at from five to six weeks, their blood secured for the agglutination test, and spleen, lungs, and liver cultured for $B r$. abortus.

Blood Agglutination Test.-Four dilutions of blood serum were made as a routine procedure by directly pipetting $0.020,0.010,0.005$, and 0.002 ec of serum, to which 1.0 ec of antigen was added, thus making dilutions of 1-50,1-100, 1-200, and 1-500. The antigen was prepared from 48 to 72-hour growths of several strains of bovine and porcine Brucella abortus by the addition of 0.5 per cent physiological sodium chloride and after thorough shaking by hand was filtered through coarse filter paper or a thin layer of cotton. Addition of carbol-saline was then made to secure a density of 3.4 Gates reading. No attempt was made to adjust the reaction to any particular $\mathrm{pH}$ concentration. This suspension was then stored in an ice box and used when the organisms proved to be dead. The serum-antigen tubes were incubated overnight, removed to room temperature, and readings made at 24 and 48 hours.

Collection and Treatment of the Milk Samples.-Approximately 400 ce of milk constituted the usual sample, which was collected in approximately equal amounts from all milking quarters. Ordinary market-milk pint bottles were covered with a layer of fine cheesecloth, the paper cap applied, and the whole top part of the bottle covered with medium heavy wrapping paper which was tied around the neck of the bottle with string. These bottles were then sterilized in the autoclave.

Ten to 20 ce of each sample was withdrawn from the bottle in a sterile manner to provide a sample for the whey-agglutination test. The rest of the milk was distributed in large sterile test tubes and centrifuged for 
20 minutes, and the sediments mixed together and recentrifuged, so that the final sediment represented that from the entire sample. An equal quantity of the cream was always included with this final sediment for guinea-pig injection. Two guinea pigs were injected, intraperitoneally in most cases, with 2.0 ec of the mixed sediment and cream from each cow.

The portion of milk retained for the agglutination test was placed in a warming bath after the addition of a few drops of commercial rennet. When the whey had clearly separated, it was subjected to the test by using the same technique which was applied to the blood serum.

Collection and Treatment of Uterine Contents.-Whenever a fetus or a fresh and clean placenta was available, it was collected and brought to the laboratory for culturing and guinea-pig injection. In the absence of these, uterine swabs were taken. Cultures on glycerine glucose gentian-violet agar with a $\mathrm{pH}$ of $6.8-7.0$ were made from the stomach contents, spleen, and liver of every available fetus, and from the placenta or uterine swabs. At least two guinea pigs were injected intraperitoneally with these materials.

The uterine swabs were collected by means of a stiff wire, at one end of which a piece of coarse cheesecloth was wrapped lonsely and tied. The gauze end of this instrument was inserted into a large test tube, which was then sealed with a cotton plug. This was then covered with wrapping paper and the whole sterilized. In taking the uterine swab, the external genitals were thoroughly cleansed. The clean hand and arm then carried the unwrapped tube containing the gauze end of the wire to the cervical end of the vagina, where by a little manipulation the glass tube was removed from the gauze swab. The swab was then pushed into the uterus and its walls wiped until the gauze was assumed to be saturated, when it was withdrawn to the vagina, again inserted into the glass tube, brought to the outside, and recovered with the sterile paper wrapper, without having been exposed to contamination from the exterior. In the laboratory, from 10 to 15 ce of sterile physiological sodium chloride was added to sterile tubes and a suspension prepared from the swabs. The contents remaining from the washed gauze swabs were then centrifuged and the sediment cultured and injected into guinea pigs in the same manner as for the other materials already described.

\section{CORRELATION BETWEEN AGGLUTININS AND UDDER INFECTION}

Blood Agglutinins.-Simultaneous blood agglutination tests and guineapig inoculations of milk sediment from all functioning quarters were 
made on 49 cows whose history, sometime during their period of observation, showed blood agglutinins. In 38 , or 77.5 per cent, of these, Brucella abortus was isolated from the udder one or more times. With the exception of 4 cows, the organism was recovered two or more times from the 34 udders, the milk of which was examined more than once. Two hundred and thirty-five such examinations were made between the years 1922 and 1927. In addition, 127 samples of milk from 32 cows which maintained a negative blood test during the entire period of study, were tested for $B r$. abortus by guinea-pig inoculation. In no case did a cow with persistently negative blood reactions show either the organism or agglutinins in the milk in the composite sample from the udder. However, in the group of 38 animals in whose udders Br. abortus was found one or more times, a significant fact developed in relation to blood agglutinins and udder infection : 8-or over 21 per cent-of the cows shed Brucella abortus from the udder either before agglutinins appeared in the blood or at a time when the blood agglutinins had receded to negative, or to positive at a dilution of only 1-50. Special attention is called to the blood and milk-test history of these cows.

The organism was recovered from the mill of cow 357 once when the blood was completely negative at 1-50 although this animal had a previous history of agglutinins at greater concentration. However, the titer had been practically negative in 1-100 for 18 months previously and her various tests show her practically free of agglutinins in the blood. Furthermore, Brucella abortus was recovered from a normal calving 7 months and 12 days before it was found in the milk.

Cow 334 shed the organism in the milk at four successive examinations at two-month intervals when the blood was twice negative in 1-50; once positive in 1-50 only ; and once when partial in 1-100.

Brucella abortus was first present in the milk of cow 342 as long as 273 days, and again at 149 days, before the blood gave indications of agglutinins. The milk was positive for organisms on four succeeding tests over more than a year, though at these times the blood titer only once went over 1-200.

Cow 346 gave 7 positive milk tests for the organism over a period of practically two years. One of the positive tests occurred when the blood was negative in 1-50 and another when it was positive in 1-50 only.

Brucella abortus was recovered from the milk of cow 338, once 104 days and again 36 days before agglutinins appeared in the blood in a 1-50 dilution. After an interval, during which the blood became positive in 1-500 dilution, the organism was again found four consecutive times over a period of 240 days.

Cow 384 gave five positive milk cultures, one of which occurred when 
only a partial reaction was present in 1-50 dilution of blood. The blood titer one month previous was partial in 1-100, and two months after this positive milk sample, positive in 1-50 only.

Cow 380 had a similar history, and Brucella abortus was isolated five consecutive times from the udder, at two of which times the blood titer was completely negative in 1-50 over a period of three months.

Brucella abortus was isolated from the udder of cow 349 in six consecutive tests. The first isolation was made after a two-year period of negative blood tests and 67 days before the next blood test showed her to have blood agglutinins.

Discussion of Blood Agglutinins in Relation to Udder Infection.The data on this phase of the studies confirm the findings of many others, that the great majority of cows that harbor Brucella abortus in their udders show also sufficient agglutinins in the blood stream to be designated as positive reactors. However, the exceptions to the rule are of special interest from both the scientific and practical viewpoints.

The significance of the results of tests on the 8 cows that shed Brucella abortus while the blood agglutination was negative, or almost so, is apparent to anyone concerned with the control and eradication of Bang's disease. When approximately 20 per cent of udder-infected cows fail at certain periods to show sufficient agglutinins in the blood to be classed as reactors to the agglutination test, it is evident that this is at least one cause for the perpetuation of the disease in a herd and for the recurrence of reactors in certain herds where an eradication program is being carried out on the basis of the blood-agglutination test. However, the picture is not as dark as it might appear to be because the majority of animals of this type, in a herd that is frequently tested, would be identified and properly handled if intelligent supervision is operating. On the other hand, these data emphasize several points that must be kept in mind in the control of Bang's disease : (1)Brucella abortus in the udder does not necessarily stimulate the production of blood agglutinins; (2) frequent blood tests are necessary to identify the carriers; (3) cows showing agglutinins in the blood in low dilutions (1-50) may frequently be udder shedders.

Whey Agglutinins.-Unfortunately the data on whey agglutinins are of debatable significance in answer to the question of the relation of milk agglutinins to Brucella abortus in the udder because tests were made in all cases upon the milk equally mixed from all lactating quarters. Since the following data were accumulated, several investigators, as well as ourselves, have shown that only one or possibly two of the quarters may harbor Br. abortus and that the dilution of agglutinins, if present in these, by the addition of milk from the noninfected parts may 
prevent a positive whey-agglutination test. While the method employed by us for isolation of the organism from the milk through sedimentation of the entire quantity drawn seems to have been reasonably satisfactory, the data on the related agglutinins merely confirm the findings of others as previously stated.

A total of 227 whey-agglutination tests of composite samples from all functioning quarters of 49 cows in this herd were made and each checked by guinea-pig inoculations. Ninety-three samples showed complete agglutination in the 1-50 dilution or higher and the organism was present in 66 tests, or in 70.9 per cent. One hundred and thirty-four were negative in the 1-50 dilution, and yet Brucella abortus was found in 43, or in 32 per cent, of the same samples.

When the cows are grouped to include those upon which two or more whey tests were made, and each one that showed agglutinins at any of the several examinations is designated as positive for agglutinins, Brucella abortus was isolated one or more times from 26, or from 83.8 per cent, of the 31 cows qualifying in this class. On the other hand, in 8 individuals that never showed agglutinins in 1-50 or higher in the mixed milk from the four quarters, 5 , or 62 per cent, of them discharged the bacillus at some time during the period of testing.

Discussion of Data on Relation of Udder Infection and Udder Agglutinins.-Although one quarter only of an udder may contain Brucella abortus, most infected udders sooner or later have more than one quarter infected. Therefore it seems plausible that our data should have shown a higher degree of correlation between agglutinins and the presence of the organism in the composite sample of milk if this relation is of any practical value in identifying udder carriers. Our data do not indicate that the whey-agglutination test is of no value in identifying udder-shedders, but rather suggests its value as an aid in this procedure because a positive whey test in any dilution probably means udder infection. Conversely, however, the absence of agglutinins in a dilution of 1-50 was not positive proof that there were no $\mathrm{Br}$. abortus organisms present in the same udder in this infected herd. Generally the agglutinins in the whey varied considerably in concentration from time to time and were usually lower than those in the blood.

\section{CORRELATION BETWEEN BLOOD AGGLUTININS AND GENITAL INFECTION}

In Positive Cows Calving Normally.--Normal pregnancies in 47 cows known as reactors were examined by culture and guinea-pig inoculation. Brucella abortus was recovered from 12 different animals, or 25.5 per 
cent. Not all the normal calvings in these 12 animals were subjected to examination; in those examined more than once the germ was found twice in only one cow. Five of 6 pregnancies in one cow were examined and showed the germ only once. Four of the 12 had also a history of abortions with the organism present, and in 2 of these the abortions occurred subsequent to the normal pregnancy in which the parturition products were positive. Seven of the 12 cows had also a history of $\mathrm{Br}$. abortus in the udder. The milk of the other 5 was not examined.

With respect to the titer of the blood serum at the time Brucella abortus was present in the uterus at the termination of a normal pregnancy, all except 2 such animals had a history for a considerable period before and after calving of blood reactions above 1-200, usually in 1-500. Of the exceptions, cow 357 had a positive blood reaction in 1-500 from July 28,1922 , to October 15, 1924, when the titer began to go down. Between March 15, 1925, and December 18, 1926, she gave 3 negative tests in 1-50. On the latter date the titer was up to a partial in 1-100. She calved 43 days later and her blood serum was partial in 1-50. Two tests, three and six months later, were completely negative in 1-50. In 11 tests over a period of three years after that time she showed 6 negative tests in 1-50 and 5 positive in 1-50. During these three years she had three normal calves, but Br. abortus was not recovered at any of the calvings. Cow 380 had a similar blood-titer history except that at a test 45 days before the calving at which the germ was recovered, she gave a partial in 1-500, and 27 days after calving was positive in 1-200. Before and after this period, during five years' testing, the titer varied from negative in 1-50 to partial in 1-100.

In Abortions by Positive Cows.-Attention has already been called to the rise in positive reactors and abortions in 1925, 1926, and 1928. The greatest number of abortions occurred in 1926, when 23 animals aborted. For the entire period of six years, 48 , or 13.6 per cent of all pregnancies, terminated prematurely, of which 77 per cent were in positive cows, and 23 per cent in negative cows.

In the group of positive reactors there were 37 abortions. Thirty-six of these were given the routine tests for Brucella abortus, and the organism was isolated in 32 , or in 88.8 per cent, of the examinations. Of the 37 aborting cows in this positive group, all except cow 347 were detected as positive reactors before the abortion occurred, by means of tests every three months. Cow 347 should be classed as a negative cow that aborted owing to $\mathrm{Br}$. abortus; for she did not become positive until more than two months after the abortion. She is considered with the positive cows also, however, because of later temporary reactions. She had a negative agglutination history from April 2, 1923, to November 12, 
1925. On August 27, 1925, she aborted, and Br. abortus was isolated by culture and by guinea-pig injections. The agglutination tests made 62 days before the abortion and 8 days after were both completely negative. On the following test two months later, the blood titer was only partial in 1-100, remained so during one year, and then became negative for another year.

In Abortions by Negative Cows.-An unusually large number of cows, negative to the agglutination test, aborted during the period of the investigations. There were 225 negative cows pregnant, of which 11, or slightly less than 5 per cent, aborted. All except one were given the routine laboratory examinations for Brucella abortus, with the recovery of the organism from two cows, 347 and 112 . Only cows with completely negative agglutination histories are included in this group, with the exception of cow 347 , previously discussed.

No particular effort was made to determine the cause of these abortions other than the tests for Brucella abortus, because they were well distributed throughout a six-year period; and since there was so much $B r$. abortus infection present in the herd, it was assumed that the majority of these cows would become positive reactors, an assumption that did not prove true with the particular group under discussion except possibly cow 347 , referred to in the preceding group. Cow 112 was negative in 1-50 from June 22, 1922, to March 17, 1930, except for one test in September 16, 1927, when she was positive in 1-50 only. Six months and nineteen days after this test, with three negative ones in between, she aborted twin heifers. One of two guinea pigs injected with fetal stomach contents was positive for $B r$. abortus. She had had five previous calves, at normal term, and later gave birth to premature twins on two different occasions. Unfortunately, the last two premature births were not examined bacteriologically.

In Negative Cows Calving Normally.-In the study of negative cows calving normally, search was made for Brucella abortus in 134 of the normal pregnancies in 73 cows of the herd which had been consistenly negative to the agglutination test in dilution of 1-50. Among these, 4 cows, or 0.54 per cent, shed the organism at one normal calving.

Cow 138 was negative in 1-50 from December 18, 1925, to March 18, 1931 , with the exception of a test on July 13, 1928, when there was recorded a partial reaction in the 1-50 and 1-100 tubes. No other plus sign appears in her record. Sixty-two days before the partial reactions noted, Brucella abortus was recovered from uterine swabs taken immediately after calving, by culture from one of two guinea pigs injected. The other guinea pig was negative. 
Cow 322 was completely negative in all dilutions from 1-50 to 1-500 from April 2, 1923, to March 18, 1931. On March 3, 1924, she had retained placenta and parturient paresis, and two guinea pigs injected with uterine-swab suspension were positive for Brucella abortus. Two later calvings were negative.

Cow 140 was completely negative from February 19, 1926, to March 16,1928 . On September 16, 1927, she had her first calf. One guinea pig was positive by lesion and culture and the other had suspicious lesions, but the organism was not found in it.

Cow 16 was completely negative from July 8, 1922, to March 18, 1926. On October 10, 1925, she had her third calf. One of two guinea pigs inoculated with suspension from a uterine swab was positive for Brucella abortus. The other guinea pig was negative. Of two earlier calvings, one was negative and the other not examined.

Discussion of Data on Relation of Blood Agglutinins to Genital Infection.-The value of any biological test for diagnostic purposes lies essentially in its ability to consistently detect the animals that are carriers of infecting organisms or the products of their activities. It is only by the analysis of many data accumulated under varied conditions that such tests can be evaluated and their limitations circumscribed. In the data collected in this one herd under discussion, the agglutination test is shown to have a high degree of accuracy, yet it is subject to certain limitations, the knowledge of which is fundamental to practical interpretation and application.

In the group of positive cows that had some normal-term calves and some abortions, the data show that 20.3 per cent of the normal calvings were accompanied by the discharge of Brucella abortus, although it was found more than once in only 1 cow. But the more significant factors so far as the danger from these cows is concerned, were that two of the four abortions which had occurred in this group were subsequent to the positive normal calving, and the titer of 2 of the 12 cows had receded to 1-50 when they shed the organism at full-time calving. In this herd, therefore, 3.3 per cent of the cows that had been previously designated as positive reactors, and whose blood titer had decreased to and fluctuated between negative in 1-50 and positive in 1-100, were spreaders. These data illustrate the fallacy of retaining such animals in a herd in which an attempt is being made to eliminate Bang's disease, or of hoping that positive reactors may "get well" and be returned to the negative herd. Such cases may rarely occur, but this practice is certainly not to be recommended.

The ability of Brucella abortus to cause abortions and premature births was well shown in the calving records of this herd : 77 per cent of 
the cows that were or became positive blood reactors, had prematurely terminated pregnancies, and in these $B r$. abortus was isolated from genital products of 88.8 per cent of the pregnancies examined. The blood agglutinins were closely correlated with the high percentage of culture findings; only one infected cow failed to indicate by her blood titer that $B r$. abortus was present in her body and was the probable cause of the abortion. However, among the 23 per cent of abortions that occurred in so-called negative cows, one certainly showed no signs of blood agglutinins in 1-50 over a long period of time and yet shed the organism from the genital tract. Another would ordinarily have been overlooked and the abortion laid to some cause other than Br. abortus if the blood titer had been taken as the only criterion. The data in this group, together with the finding of $\mathrm{Br}$. abortus in four genital shedders among the group of always-negative cows that calved normally, point out certain limitations of the agglutination test that help to account for the difficulty that sometimes occurs in completely eradicating the disease from a herd in which a high percentage of infection originally existed. These negative cows that aborted or calved normally accompanied by the discharge of $\mathrm{Br}$. abortus, were all tested by the agglutination test sufficiently long and frequently before and after calving to say positively that no agglutinin formation indicated the presence of the organism in the body. Since in three of the latter cases only one of two guinea pigs, injected from each cow, showed positive lesions and cultures, it may be assumed that the organisms were so few in number that a real infection was not established in the host.

The study of the agglutination-test reactions in this herd over a period of several years has shown the usual interesting and possibly disturbing variations in relation to known or unknown infection with Brucella abortus. The data, though not all included in this report, clearly divide the cows into three classes with reference to their blood titers : (1) those that remain persistently negative in all dilutions from 1-50 and above, (2) those that continue as definitely positive reactors from 1-200 and above, and (3) those that vary at different tests from negative in 1-50 to positive from that point upward. Perhaps a subdivision of the latter class would include those that show a definitely declining titer after a long period of high titers.

In group 1 are records of 36 cows, not including bulls, which have been tested regularly from five to eight years without a single positive sign in any of the many tests. Most of these cows have undoubtedly been exposed to Brucella abortus, for they have been in the herd while from 12 per cent to 36 per cent of the animals were reactors. All of them passed through the high peak of reactions and abortions in 1925 and 
1926. Eleven of them have aborted, but Br. abortus was found in the uterus of only 1 . Such data justify the conclusion that many cows have a high degree of natural resistance against ordinary herd exposure to Bang's disease.

Group 2 includes 14 animals that have given regularly high reactions in at least 1-500 for a period of from four to six years. Ten have aborted or discharged Brucella abortus at normal calvings. The agglutination test has a high rating in this group as a diagnostic test.

In the third class are 23 cows whose agglutination-test history over a period of from four to eight years is one of oscillating titers for lengthy periods, for the most part following high ones. This group is by no means free from the serious results of the infection because there are 10 abortions, 4 genital shedders at normal calvings, and infected udders to be found in it. It also contains most of the exceptions noted in the preceding pages regarding the correlation of blood and milk agglutinins to infection. The most practical point to consider with respect to these animals is whether or not they were free of the organisms after a period of negative blood tests following a history of infection. The records show that at least 5 of them were not, but were still carriers. More may have been.

The data from this herd are not extensive nor individual records complete in all cases on the subject of natural recovery from Bang's disease in the sense that the body no longer harbors the organisms, but they tend to the conclusion that it is rare in the average life of a cow. Some few have shown declining titers to negative tests after four or five years of positive reactions; but according to the data accumulated in these studies, great caution must be exercised in giving a clean bill of health to positive cows whose titers become low or negative over a considerable period of time. Some of these again show agglutinins and continue to be spreaders at irregular intervals.

\section{FREQUENCY AND SEQUENCE OF ABORTIONS IN POSITIVE COWS}

Under the conditions surrounding this herd, pregnant cows of all ages are assumed to have been equally exposed to the infection, although there may have been slightly less opportunity for first-pregnant heifers in that they were not in the milking strings. However, the space was limited and very general use was made of the same corrals for dry cows, heifers, and young bulls. So far as this herd is concerned, first-calf heifers showed less tendency to abort than did those in their second and third pregnancies. 


\section{BRUCELLA ABORTUS INFECTION IN A YOUNG BULL}

In July, 1926, an Ayrshire bull, fifteen months old, in the herd but not yet in service, developed an orchitis in the left testicle (fig. 1). Abortion infection was suspected, and a blood sample taken agglutinated Bru-

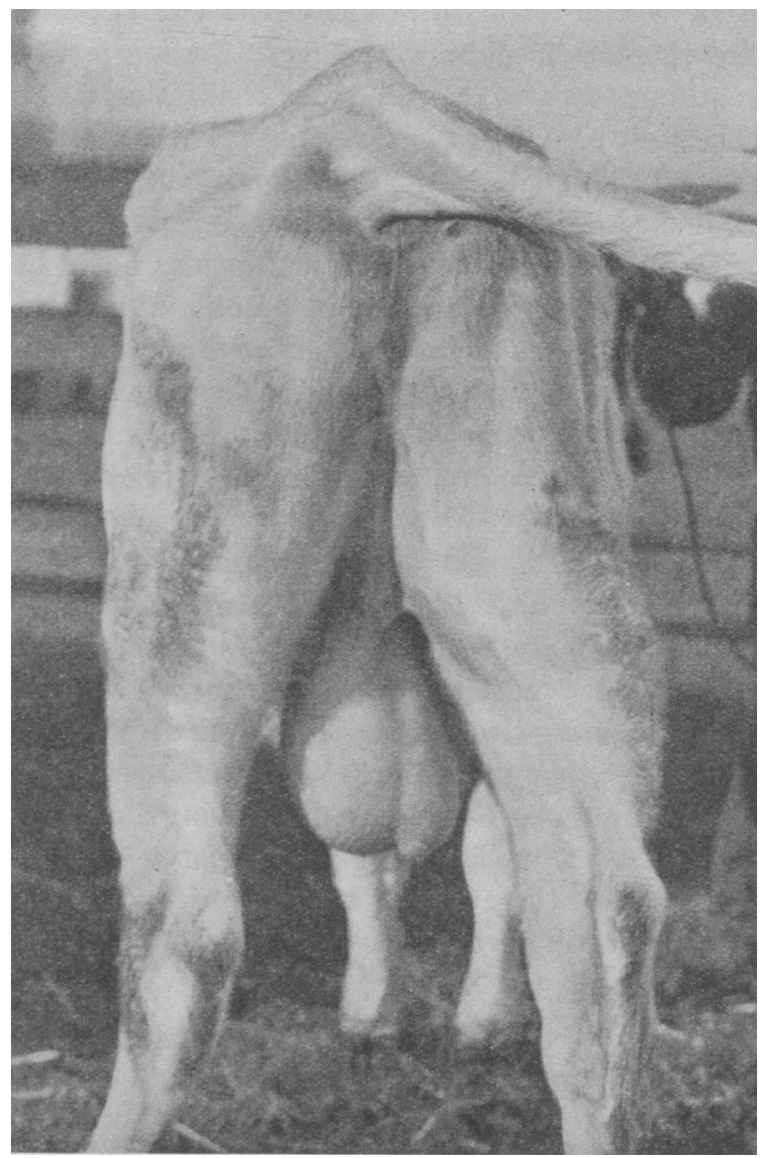

Fig. 1.-Ayrshire bull showing orchitis in left testicle due to Brucella abortus.

cella abortus antigen in 1-500 dilution. No higher dilutions were made. He had some contact with abortion-infected females from birth until eleven months of age. His dam had been a positive reactor at least since 1922 but had normal calves. As a calf the bull probably consumed mixed milk from the whole herd. 
In order to ascertain whether or not Brucella abortus was being discharged through the urine, five samples of urine were collected during November and December. Approximately 1 liter was secured each time

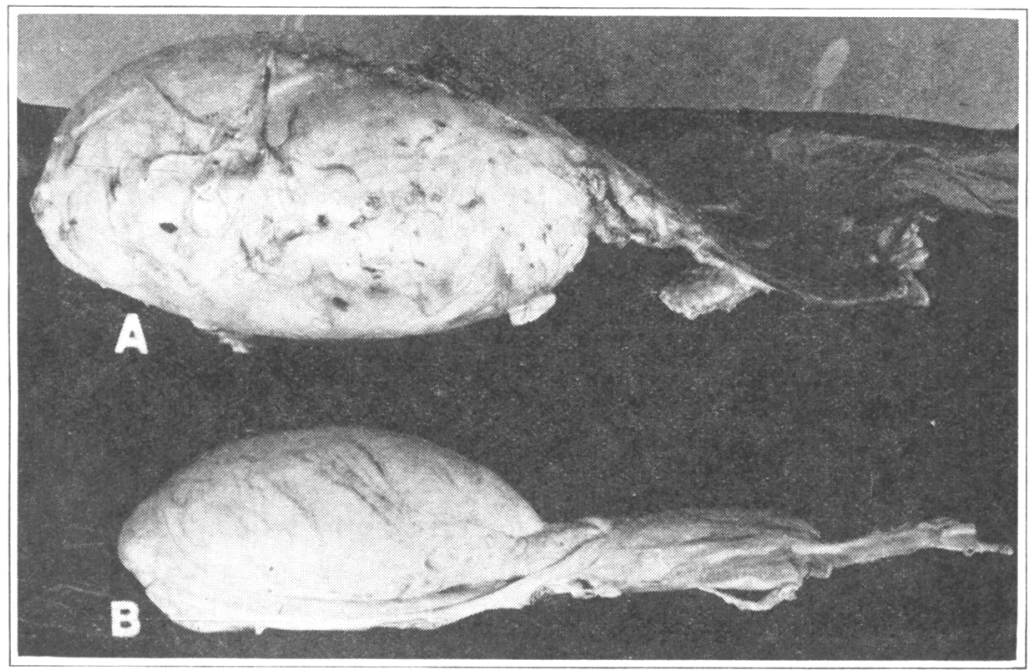

Fig. 2.- $A$, Pathological testicle from Ayrshire bull shown in figure $1 ; B$, normal testicle from same animal.

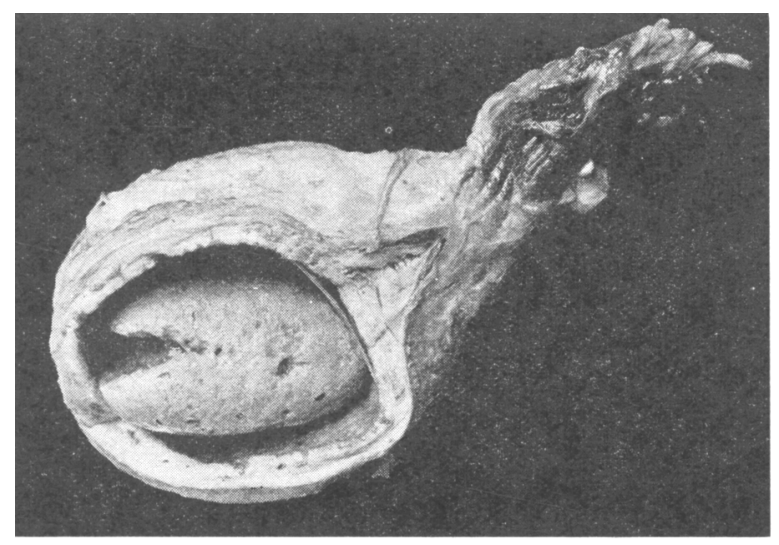

Fig. 3.-Appearance of opened pathological testicle from Ayrshire bull shown in figure 1.

and sedimented by centrifugation. Sterile saline was added to the sediment and 3 cc injected intraperitoneally into each of two guinea pigs. Several guinea pigs died in a few days from injections of the urine. The result of the injection into guinea pigs that lived to be autopsied and cultured show that the first sample, collected on November 15, 1926, con- 
tained Br. abortus and that the other four samples were negative for the organism.

The bull was destroyed on February 11, 1927, and the following autopsy notes were made :

Infected testicle (figs. $2 A$ and 3 ) measures $23 \mathrm{~cm} \times 13 \mathrm{~cm}$ when skin is removed. Normal testicle measures $15 \mathrm{~cm} \times 8 \mathrm{~cm}$. The various tunies have undergone fibrosis to form a wall $1.5 \mathrm{~cm}$ thick. On section the wall shows numerous yellow foci $2 \mathrm{~mm}$ in diameter, which contain a caseous pus. The remains of the testicle float in approximately 500 ce of grey-yellow pus without odor, and is completely separated from its supporting structures. It resembles a testicle only in shape and size. The surface is of grey-yellow color and contains several crater-like erosions. The entire surface is roughened and has a granular appearance. Neither the vas deferentia nor epididymus can be observed within the fibrous sac. Outside the sac the spermatic vessels appear normal.

Cultures and guinea-pig inoculations were made from the following structures : prepuce, urethra, seminal vesicles, urine and mucosa from bladder, deep inguinal glands, infected testicle and normal testicle. At time of death the blood serum was positive up to 1-500. The results of the guinea-pig and culture inoculations showed the presence of Brucella abortus in the bladder and deep inguinal glands. Negative results were obtained from the other structures.

\section{RESULTS OF SEPARATING THE POSITIVE AND NEGATIVE REACTORS}

Failure to control the disease by sanitation and hygiene in connection with aborting cows, and the great increase in abortions that occurred in 1925 and 1926 led those in charge of the herd to divide the negative and positive cows so that the two groups occupied corrals and milking stalls on opposite sides of the milking barn. This type of separation was made on March 18, 1926. It was realized that this plan would not be wholly sufficient to prevent the spread of the disease, but other space was not then available. Table 1 shows the results of repeated agglutination tests and the separation of the negative and positive groups. Additional reactors were expected to be found since there were about 37 per cent reactors in the herd when the segregation was made. However, after a trial of eighteen months under the above plan, during which reactors were found in the so-called negative herd, all cows showing complete agglutination at 1-50 were removed to entirely new premises on the same ranch at a distance of $1 / 4$ mile. A special herdsman took charge of them and neither he nor any of the equipment came in contact with the negative group that was left on the old infected premises. No attempt was made to clean and disinfect the corrals to be occupied by the clean herd. 
Since September, 1927, only 2 new reactors have been found, and none from the test of March, 1929, to the last test recorded in March, 1935.

Approximately 56 animals were removed from the herd as reactors to the agglutination test between September, 1927, and March, 1929. Fifteen of these became definitely sterile, 13 died or were destroyed for various disease conditions, and 18 were sold as reactors, and their history, from this time, is not available. During the entire time of segrega-

TABLE 1

Results from Repeated Agglutination Tests and Segregation of Reactors

\begin{tabular}{|c|c|c|c|c|c|c|c|}
\hline Date of test & $\begin{array}{l}\text { Total } \\
\text { tested }\end{array}$ & Reactors & Per cent & Date of test & $\begin{array}{l}\text { Total } \\
\text { tested }\end{array}$ & Reactors & Per cent \\
\hline${ }^{*}$ March, $1926 \ldots \ldots$ & 115 & 43 & 37.4 & September, 1929. & 84 & $\mathbf{0}$ & 0.0 \\
\hline June, $1926 \ldots \ldots \ldots$ & 66 & 3 & 4.5 & March, $1930 \ldots$ & 103 & $\mathbf{0}$ & 0.0 \\
\hline September, 1926.. & 66 & 3 & 4.5 & September, $1930 \ldots$ & 90 & $\mathbf{0}$ & 0.0 \\
\hline December, $1926 \ldots$ & 75 & 1 & 1.3 & March, $1931 \ldots \ldots$ & 91 & 0 & 00 \\
\hline March, $1927 \ldots \ldots$ & 71 & 1 & 1.4 & September, $1931 \ldots$ & 99 & 0 & 0.0 \\
\hline June, $1927 \ldots \ldots \ldots$ & 83 & 2 & 2.4 & March, $1932 \ldots \ldots$ & 109 & 0 & 0.0 \\
\hline †September, 1927.. & 80 & 1 & 1.2 & September, 1932... & 117 & 0 & 0.0 \\
\hline December, $1927 .$. & 76 & 0 & 0.0 & March, $1933 \ldots \ldots$ & 110 & 0 & 0.0 \\
\hline March, $1928 \ldots \ldots$ & 78 & 0 & 0.0 & March, $1934 \ldots . .$. & 104 & 0 & 0.0 \\
\hline September, 1928.. & 81 & 1 & 1.2 & October, $1934 \ldots \ldots$ & 97 & 0 & 0.0 \\
\hline March, $1929 . \ldots \ldots$ & 96 & 1 & 1.0 & March, $1935 \ldots \ldots$ & 94 & 0 & 0.0 \\
\hline
\end{tabular}

* Following the March, 1926, test, the reactors were separated from the nonreactors by keeping the two groups in corrals on opposite sides of the milking barn when milked. The same caretakers handled both groups.

$t_{1}^{\prime}$ On!October 27, 1927, after the test of September, 1927 , all'of:the reacting cows were moved to separate quarters about $1 / 4$ mile away and placed in charge of a special herdsman. On account of certain breeding experiments, itthas been necessary to breed the reacting cows to negative bulls by bringing the former to neutral ground within the confines of the nonreacting group.

tion, the positive herd has been an economic liability because of sterility and an unusually high percentage of various disorders. All except 1 continued to give positive agglutination tests in a dilution of at least 1-500, until slaughter or death from disease. The one exception first reacted in 1922 and became negative in 1-50 in 1925, and continued to give negative reactions until September; 1930, when she again became positive in 1-200 for almost a year. Two of the original positive herd are still alive (May, 1935) but one is apparently sterile. Both have continued to be high reactors since 1925 and 1927 respectively, and both are still udder shedders.

\section{SUMMARY AND CONCLUSIONS}

Of the cows reacting positively to the blood-agglutination test, 77.5 per cent showed udder infection.

Cows in an infected herd may have Brucella abortus in their udders for a considerable period before agglutinins appear in the blood stream. 
In 3 cases out of 38 , the organism was present in the milk 8 months, 13 days; 5 months, 25 days; and 3 months, 14 days, respectively, before blood agglutinins were demonstrable.

The milk from udders harboring Brucella abortus frequently does not contain sufficient agglutinins to be detected by the usual whey-agglutination test in dilutions as low as 1-50 when a composite sample from all quarters is tested.

Udders of cows having a positive blood history may continue to carry Brucella abortus when the blood titer has declined to negative in a dilution of 1-50.

Cows with declining and low fluctuating blood titers may be spreaders at normal calvings when the titer is as low as negative in 1-50.

Of the cows reacting positively to the blood-agglutination and calving normally, 25.5 per cent expelled Brucella abortus at parturition.

Cows in an infected herd but with a consistently negative blood reaction in 1-50 over a long period of time, do occasionally ( 0.54 per cent) discharge Brucella abortus at a normal parturition. Likewise abortions in cows of this type were accompanied by the discharge of the organism with the fetus in 0.4 of 1 per cent of the abortions in this herd.

Recovery from Bang's disease is rare in the average life of a cow, and cows with a definite and long-standing positive blood history cannot safely be given a clean bill of health after a few negative tests.

Complete removal from the herd of all cows that show agglutinins in 1-50 was the only type of segregation that prevented the spread of Bang's disease in this herd. The data suggest that when this type of segregation fails, search should be made for nonreacting cows which are shedding Brucella abortus in the milk. 